\title{
Performance of Three Tropical Hair Sheep Breeds ${ }^{1}$
}

\author{
M. H. Rajab*, T. C. Cartwright ${ }^{\dagger}$, P. F. Dahm*, and E.A.P. Figueiredo ${ }^{*, t, 2}$ \\ *Department of Statistics and 'Department of Animal Science, \\ Texas A\&M University, College Station 77843
}

ABSTRACT: The performance of three hair
sheep breeds (Brazilian Somali, Morada Nova,
and Santa Ines) was evaluated in the production
environment of northeastern Brazil. Data from a
total of 524 lambs sired by 21 rams and out of 190
ewes were analyzed. These data were collected
from 1980 to 1983 at Sobral, Brazil from an
experiment designed to compare performance of
the three breeds. The traits included weights of
lambs at birth, weaning, 8 mo, 10 mo, and yearling
ages and ewe characters of weight at lambing
(EWT), total lamb weight born (LWB), total lamb
weight weaned (LWW, and prolificacy rate (PR).
Differences (P < .01) among breeds were found for
all characters. The Brazilian Somali, the smallest and slowest-gaining breed, was less sensitive to yearly variation than were the other breeds. The Santa Ines, the largest and fastest-gaining breed, was superior in LWB and LWW per ewe lambing. Averaged over the 4-yr period, the Morada Nova had the highest PR (1.82), and the Brazilian Somali and Santa Ines had similar PR (1.39 and 1.31, respectively). Environmental effects on PR due to yearly rainfall quantity and distribution pattern influenced lamb growth up to weaning and ewe reproduction performance. Breed $\times$ year $(P<.05)$ interaction effects on PR were largely attributable to the Somali breed's exhibiting higher PR than the Santa Ines and Morada Nova breeds during the relatively wet years of 1981 and 1982 .

Key Words: Sheep, Performance, Brazil, Genotype Environment Interaction

J. Anim. Sci. 1992. 70:3351-3359

\section{Introduction}

Small ruminants have an essential role and contribute significantly to the economy and survival of rural people of the tropics. One of the larger populations of hair sheep in the Americas is found in the northeastern region of Brazil. Three prevalent sheep breeds in northeastern Brazil are the Morada Nova, Brazilian Somali, and Santa Ines. Distinct differences among the three breeds are evident for mature size and prolificacy (Figueiredo et al., 1983).

According to Bradford (1985), environments with scarce forage that are highly variable among seasons and years, and where supplemental feed is scarce and uneconomic, would only support

\footnotetext{
${ }^{1}$ Data were collected and made available by CNPC, EMBRAPA at Sobral, Brazil. This study was supported in part by funds from the U.S. Agency for Int. Dev, Title XII, Small Ruminant Collaborative Res. Support Program under grant No. AID/DSAN/XII-G-0049.

${ }^{2}$ Present address: EMBRAPA, CNPC, Sobral, Ceara, Brazil. Received February 14, 1882.

Accepted July 3, 1982.
}

sheep with single births. However, if such environments permit supplementation at critical times, twinning from mature ewes could be tolerated. Differences among domestic sheep breeds for reproductive characteristics have been described by Glimp (1971), Sidwell and Miller (1971), and Bradley et al., (1972).

The objectives of this study were 1) to provide comparative information on growth and prolificacy of Morada Nova, Brazilian Somali, and Santa Ines breeds in northeastern Brazil, 2) to examine the effects of environmental variables and breeds and interactions of these effects on ewe production and lamb production per ewe, and 3) to evaluate differences among the productivity (lamb growth and production) of flocks of the three breeds.

\section{Materials and Methods}

Data from the three breeds were collected from 1980 to 1883 at Centro Nacional de Pesquisa de Caprinos (CNPC), EMBRAPA, Sobral, Brazil. During this period flocks of these breeds were main. 
tained on native pasture and management practices remained relatively stable. The data were collected from 524 lambs, 190 ewes, and 21 rams (Table 1) of the three breeds and included breed; sex; weight at birth, weaning, $8 \mathrm{mo}, 10 \mathrm{mo}$, and 12 mo age; type of birth (single, twin); and ewe age and weight at lambing.

In this region of Brazil the rainfall pattern divides the year into two distinct seasons: a rainy season that usually starts during December or January and ends in May or June, and a dry season that lasts the rest of the year. This dry period may extend to 10 or 11 mo during periodic droughts. The precipitation in this area usually ranges from 400 to $800 \mathrm{~mm} / \mathrm{yr}$ and is irregularly distributed during the rainy season. Hence, quantity and quality of the forage available for grazing vary according to the seasonality and the distribution of the rainfall. Temperature in this tropical region (latitude of approximately $5^{\circ} \mathrm{S}$ ) has little seasonal variation. More detailed descriptions of this experiment have been given by Figueiredo (1986) and Rajab (1987).

The sheep production system in northeastern Brazil is based on grazing natural forages consisting of a heterogeneous mix of shrubs, small trees, and native grasses and legumes collectively called "caatinga." The caatinga is highly dependent on the rainy season for forage production. It usually

Table 1. Distribution of number of lambs, sires, and dams of the three breeds included in the study

\begin{tabular}{|c|c|c|c|}
\hline $\begin{array}{l}\text { Main } \\
\text { effect }\end{array}$ & $\begin{array}{l}\text { No. of } \\
\text { lambs }^{a}\end{array}$ & $\begin{array}{c}\text { No. of } \\
\text { sires }\end{array}$ & $\begin{array}{l}\text { No. of } \\
\text { dams }\end{array}$ \\
\hline \multicolumn{4}{|l|}{ Breed } \\
\hline Somali & $18 B$ & 7 & 71 \\
\hline Santa Ines & 120 & 7 & 48 \\
\hline Morada Nova & 206 & 7 & 71 \\
\hline \multicolumn{4}{|l|}{ Sex } \\
\hline Male & 280 & - & - \\
\hline Female & 244 & - & - \\
\hline \multicolumn{4}{|l|}{ Type of birth } \\
\hline Single & 248 & - & - \\
\hline Twin & 276 & - & - \\
\hline \multicolumn{4}{|l|}{ Year of birth } \\
\hline 1980 & 107 & - & - \\
\hline 1981 & 117 & - & - \\
\hline 1982 & 125 & - & - \\
\hline 1983 & 175 & - & - \\
\hline \multicolumn{4}{|l|}{ Age of ewe, yr } \\
\hline 2 & 108 & - & - \\
\hline 3 & 75 & - & - \\
\hline 4 & 63 & - & - \\
\hline 5 & 87 & - & - \\
\hline 6 & 80 & - & - \\
\hline 7 & 66 & - & - \\
\hline 8 & 35 & - & - \\
\hline Total & 524 & 21 & 180 \\
\hline
\end{tabular}

${ }^{a}$ Number at birth. remains green from January to June and then loses its leaves, due to lack of moisture during the dry season, forming a litter on the ground on which the sheep feed (Pfister, 1983).

Data for this study were collected during a 4-yr period (1980 to 1983). All years were below the 43-yr average rainfall $(740 \mathrm{~mm}$ ). Two years (1980 and 1983) were relatively dry years and the others were relatively wet years. The rainfall pattern in 1981 was very erratic, although it was more evenly distributed during the 1982 rainy season. Animals of the three breeds were allowed to graze and(or) browse on the native vegetation during the rainy season, and during the dry season they were allowed to graze reserved paddocks and each ewe received approximately $200 \mathrm{~g}$ of chopped Napier grass per day (Figueiredo, 1980). The breeding season lasted for $60 \mathrm{~d}$ from mid-October to mid. December.

Observations were recorded on fixed dates rather than at fixed ages; therefore, variation in age made estimation of weight at the desired age essential. Adjustment to a standard age was accomplished by interpolation between weight dates bracketing the standard age specified (Warwick and Cartwright, 1958).

Growth traits analyzed were weights of lambs at birth (BWT), weaning (WW), $8 \mathrm{mo}(8 \mathrm{~W}$ ), and 10 mo (10W), and yearling (YW) ages. The SAS (1982) software was used to analyze these data using the GLM procedure. The equation for the linear model used to obtain least squares mean estimates of BWT, WW, 8W, 10W, and YW for the lambs was as follows:

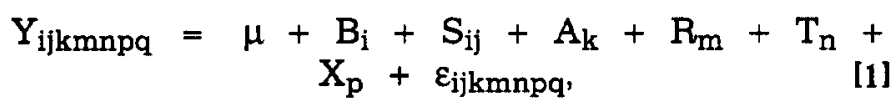

where $Y_{i j k m n p g}=$ observed value on $q^{\text {th }}$ animal with $\mathrm{p}^{\text {th }}$ sex, $\mathrm{n}^{\text {th }}$ type of birth, $\mathrm{m}^{\text {th }}$ year of birth, $\mathrm{k}^{\text {th }}$ age of dam, sired by the $j^{\text {th }}$ sire of the $i^{\text {th }}$ breed; $\mu$ $=$ common mean; $B_{i}=$ the fixed effect of the $i^{\text {th }}$ breed; $i=1,2,3 ; S_{i j}=$ the random effect of the $j^{\text {th }}$ sire in the $i^{\text {th }}$ breed, $j=1,1, \ldots, 21_{j} A_{k}=$ the fixed effect of the $k^{\text {th }}$ age of dam (year), $k=2, \ldots, 8 ; R_{m}$ $=$ the fixed effect of the $\mathrm{m}^{\text {th }}$ year of birth, $\mathrm{m}=1,2$, 3,$4 ; T_{n}=$ the fixed effect of the $n^{\text {th }}$ type of birth, $n$ $=1,2 ; X_{p}=$ the fixed effect of the $p^{\text {th }}$ sex, $p=1,2$, and $\varepsilon_{\mathrm{ijkmnpq}}=$ random error associated with the individual record.

In seeking a model to represent the relationship between measures of lamb growth, especially BWT and WW, and age of dam, the sum of squares for age of dam was partitioned into variation due to linear regression, variation due to quadratic effect, and departure from the quadratic model. Breed differences were tested against the sire within breed effect. The significance of all 
Table 2. Analysis of variance of weights of lambs at birth (BWT), weaning (WW), 8 months (8W), 10 months (10W), and yearling (YW) ages

\begin{tabular}{|c|c|c|c|c|c|c|c|c|c|c|}
\hline \multirow{2}{*}{$\begin{array}{l}\text { Source of } \\
\text { variation }\end{array}$} & \multicolumn{2}{|c|}{ BWT } & \multicolumn{2}{|c|}{ WW } & \multicolumn{2}{|c|}{$8 W$} & \multicolumn{2}{|c|}{$10 \mathrm{~W}$} & \multicolumn{2}{|c|}{ YW } \\
\hline & $d f$ & $F$ & df & $F$ & df & F & $\mathrm{df}$ & F & $d f$ & $\mathbf{F}$ \\
\hline Breed (B) & 2 & ** & 2 & $\star \star$ & 2 & $\star \star$ & 2 & $\star \star$ & 2 & ** \\
\hline Sire/B & 18 & ** & 18 & $*$ & 18 & * & 18 & * * & 16 & * \\
\hline $\operatorname{Sex}(X)$ & 1 & ** & 1 & ** & 1 & $\bullet$ & 1 & $\star \star$ & 1 & ** \\
\hline Type of birth (T) & 1 & 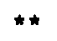 & 1 & $\star \star$ & 1 & $\star \star$ & 1 & $\star \star$ & 1 & * * \\
\hline Year of birth (R) & 3 & $\star \star$ & 3 & ** & 3 & - & 3 & $\star$ & 3 & $\star \star$ \\
\hline Age of dam (A) & 6 & ** & 6 & ** & $\theta$ & * & 6 & $t$ & 6 & NS \\
\hline Linear & 1 & ** & 1 & $\star \star *$ & 1 & + & 1 & NS & 1 & NS \\
\hline Quadratic & 1 & $\star$ & 1 & $\star \star$ & 1 & $\bullet$ & 1 & NS & 1 & NS \\
\hline Departure & 4 & $t$ & 4 & $N^{a}$ & 4 & NS & 4 & NS & 4 & NS \\
\hline Age of lamb (G) & - & - & 1 & $\star *$ & 1 & ** & 1 & * & 1 & $\pi *$ \\
\hline
\end{tabular}

${ }^{a} \mathrm{NS}=P>.10$.

${ }^{+} P<.10$.

$\star P<.05$

$m m p<.01$.

other terms was tested against the model error mean squares.

The ewes and their lambs were weighed within $24 \mathrm{~h}$ of lambing and the lambs were weighed again at weaning. The ewe reproductive characters analyzed were total weight born per lambing (LWB), total weight weaned per weaning (LWW), and prolificacy rate per lambing (PR). The equation for the linear model used to obtain least squares mean estimates of LWB and LWW for the ewes was as follows:

$$
Y_{i j k m n p}=\mu+\underset{R T_{m n}+B_{i j k m n p}}{B_{i j}+A_{k}}+R_{m}+T_{n}+
$$

where all terms are defined as above. The year of birth $\times$ type of birth of lambs interaction term was found significant and thus is included in the model.

Prolificacy rate for a breed was defined as the average number of lambs born per ewe lambing for that breed. Individual ewe prolificacy rates were 1 or 2 for single and twin births, respectively. The equation for the model used to obtain least squares mean estimates of PR for the ewes was as follows:

$\begin{aligned} \mathrm{Y}_{\mathrm{ikmn}}=\mu+\mathrm{B}_{\mathrm{i}} & +\mathrm{A}_{\mathrm{k}}+\mathrm{R}_{\mathrm{m}}+\mathrm{BR}_{\mathrm{im}}+\underset{ }{+\mathrm{AR}_{\mathrm{km} m},} \\ & {[3] }\end{aligned}$

where all terms are defined as above.

The equation used to analyze ewe lambing weight (EWT) was as follows:

$$
\begin{aligned}
Y_{i k m n q}=\mu & +B_{i}+A_{k}+R_{m}+T_{n}+R T_{m n} \\
& +B R_{i m}+\varepsilon_{i k m n q},
\end{aligned}
$$

where all terms are defined as above.

In the preliminary analysis of all the above models, contributions of main effects and all twofactor interactions were examined. Nonsignificant $(P>.10)$ two-factor and all three-factor and higherorder interactions were pooled with the model error term.

\section{Results and Discussion}

\section{Lamb Growth Rate}

The analyses of variance for weights of lambs at birth, weaning, $8 \mathrm{mo}, 10 \mathrm{mo}$, and yearling ages are presented in Table 2. The percentage contribution of the factors included in the model to the total variation in BWT, WW, and $\mathrm{YW}$ are given in Figure 1. The least squares means for BWT, WW, $8 \mathrm{~W}, 10 \mathrm{~W}$, and $\mathrm{YW}$ are presented in Table 3.

Relatively speaking, BWT was more affected by year differences than WW (Figure 1). In general, WW is considered to be more affected by fluctuations of environmental factors, such as milk and forage, than BWT (Eltawil et al., 1970). Even though BWT is affected by changes of dam nutrition and body condition, fetuses of pregnant ewes tend to receive priority of nutrient utilization (Blackburn and Cartwright, 1987) and, therefore, are, to a degree, protected from environmental fluctuations of range conditions.

However, environmental conditions, especially those that are climate-related in the northeastern region of Brazil, tend to be stressful. The breeding and gestation periods coincided with the dry season, as is customary in this region. The length and severity of the dry seasons, which have a significant effect on the variability of pregnant ewe body weight and condition, varied greatly from year to year. Thus, even though pregnant ewes tend to protect their fetuses from external environmental fluctuation, lamb BWT was af- 


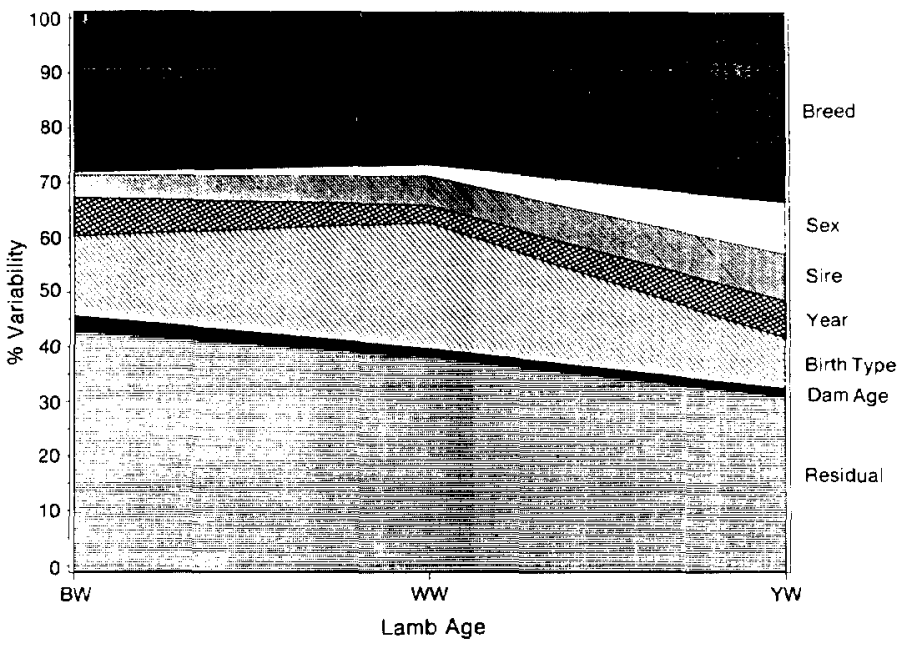

Figure 1. Percentage of contribution to total variance of breed, sex, sire, year, birth type, dam age, and residual, in descending order, in lamb birth weight (BWT), weaning weight (WW), and yearling weight (YW).

fected by yearly variation in rainfall. On the other hand, the lambing season coincided with the beginning of the wet season, during which time forage was most abundant. Thus, lambs were exposed to minimal environmental stresses from birth to weaning.
Comparisons of least squares means of BWT for one wet year (1982) and one dry year (1980) indicate that on average there was a difference $(P$ $<.01)$. In addition, differences $(P<.01)$ were found between BWT of the two wet years (1981 and 1982). The year least squares means for WW and YW also showed considerable year effects, but year differences in weight at 8 and 10 mo were small. These differences indicate that, in general, both quantity and distribution of rainfall were factors in determining lamb weights for the prevailing production practices. Studies conducted in the northeastern region of Brazil (Fernandes, 1985; Figueiredo, 1986) reported similar effects of year of birth on growth characters of Morada Nova sheep.

Type of birth had an effect $(P<.01)$ on all lamb growth characters. Single-born lambs were heavier at birth than those born with a twin, and the relative effect of these differences persisted throughout the 1st yr (Figure 1). Differences due to type of birth might be more important under arid conditions than under farm management (Eltawil et al., 1970). Phillips et al. (1940) found that singleborn lambs were heavier than twin-born lambs throughout the 1st yr in range sheep. Phillips and Dawson (1940) found that differences in farm flocks due to type of birth tended to disappear by the time the lambs reached 1 yr of age.

In general, single-born lambs have been reported to grow at a faster rate than lambs born

Table 3. Least squares means (LSM) and standard errors (SE) for weights of lambs at birth (BWT), weaning (WW), 8 months $(8 \mathrm{~W}), 10$ months, and yearling (YW) ages

\begin{tabular}{|c|c|c|c|c|c|c|c|c|c|c|c|c|c|}
\hline \multirow{2}{*}{$\begin{array}{l}\text { Main } \\
\text { effect }\end{array}$} & \multicolumn{2}{|c|}{ BWT, kg } & \multicolumn{3}{|c|}{ WW, kg } & \multicolumn{2}{|c|}{$8 \mathrm{~W}, \mathrm{~kg}$} & \multicolumn{3}{|c|}{$10 \mathrm{~W}, \mathrm{~kg}$} & \multicolumn{3}{|c|}{ YW, kg } \\
\hline & LSM & $\pm S E$ & LSM & \pm & SE & LSM \pm & SE & LSM & \pm & SE & LSM & \pm & SE \\
\hline \multicolumn{14}{|l|}{ Breed } \\
\hline Somali & $2.0 \pm$ & .1 & 13.8 & \pm & .5 & $17.0 \pm$ & .8 & 18.8 & \pm &.$\theta$ & 19.8 & \pm & 1.0 \\
\hline Santa Ines & $2.8 \pm$ & .1 & 10.4 & \pm & .6 & $25.2 \pm$ & .9 & 27.0 & \pm & .9 & 26.8 & \pm & 1.0 \\
\hline Morada Nova & $2.4 \pm$ & .1 & 15.8 & \pm & .6 & $20.5 \pm$ & 8 & 22.4 & \pm & 1.1 & 25.0 & \pm & 1.2 \\
\hline \multicolumn{14}{|l|}{ Sex } \\
\hline Male & $2.4 \pm$ & .1 & 17.0 & \pm & .4 & $21.2 \pm$ & .6 & 24.5 & \pm & .8 & 26.2 & \pm & .8 \\
\hline Female & $2.3 \pm$ & .1 & 15.7 & \pm & .4 & $20.6 \pm$ & .6 & 21.8 & \pm & .8 & 21.0 & \pm & .7 \\
\hline \multicolumn{14}{|l|}{ Type of birth } \\
\hline Single & $2.7 \pm$ & .1 & 18.6 & \pm & .4 & $22.8 \pm$ & .6 & 24.7 & \pm & .7 & 25.4 & \pm & .8 \\
\hline Twin & $2.1 \pm$ & .1 & 14.1 & \pm & .4 & $19.0 \pm$ & .6 & 21.6 & \pm & .7 & 21.8 & \pm & .8 \\
\hline \multicolumn{14}{|l|}{ Year of birth } \\
\hline 1980 & $2.3 \pm$ & .1 & 15.7 & \pm & .5 & $20.0 \pm$ & .9 & 24.6 & \pm & 1.0 & 21.5 & \pm & 1.2 \\
\hline 1981 & $2.1 \pm$ & .1 & 16.6 & \pm & .5 & $21.7 \pm$ & .7 & 23.8 & \pm &.$\theta$ & 27.7 & \pm & 1.0 \\
\hline 1982 & $2.8 \pm$ & .1 & 17.8 & \pm & .4 & $21.3 \pm$ & .7 & 23.2 & \pm & 1.1 & & - & \\
\hline 1983 & $2.4 \pm$ & .1 & 15.2 & \pm & .5 & $20.6 \pm$ & .8 & 20.8 & \pm & .8 & 21.6 & \pm & 1.1 \\
\hline \multicolumn{14}{|l|}{ Age of dam, yr } \\
\hline 2 & $2.2 \pm$ & .1 & 15.5 & \pm & .4 & $20.1 \pm$ & .7 & 22.0 & \pm & 8 & 22.8 & \pm & .9 \\
\hline 3 & $2.4 \pm$ & .1 & 16.4 & \pm & .5 & $20.8 \pm$ & .7 & 23.4 & \pm & .8 & 23.8 & \pm & 1.0 \\
\hline 4 & $2.3 \pm$ & .1 & 15.7 & \pm & .5 & $20.4 \pm$ & .8 & 22.5 & \pm & 1.1 & 22.8 & \pm & 1.5 \\
\hline 5 & $2.4 \pm$ & .1 & 16.7 & \pm & .5 & $21.4 \pm$ & .7 & 23.5 & \pm & .8 & 24.2 & \pm & 1.0 \\
\hline 6 & $2.6 \pm$ & .1 & 17.4 & \pm & .5 & $22.3 \pm$ & .7 & 24.7 & \pm & .9 & 25.5 & \pm & 1.2 \\
\hline 7 & $2.4 \pm$ & .1 & 16.7 & \pm & .5 & $20.9 \pm$ & .7 & 22.8 & \pm & .9 & 23.3 & \pm & 1.1 \\
\hline 8 & $2.4 \pm$ & .1 & 16.1 & \pm & .6 & $20.5 \pm$ & .8 & 22.8 & \pm & 1.0 & 22.9 & \pm & 1.1 \\
\hline
\end{tabular}

\footnotetext{
${ }^{\text {a }}$ Data were not available.
} 
and raised as twins because of competition for milk. Type of birth explained a greater portion of the variability of weight at weaning than at birth or yearling ages (Figure 1). However, the lower amount of milk available for each twin lamb may cause twins to start grazing earlier than singles, which can compensate for some of the disadvantage (Kilkenny, 1978). Also, part of the type of birth differences at postpartum ages might be due to the carry-over of the heavier weight of singles at birth. Reports from a wide range of production conditions and other breeds (Brown et al., 1961; Sidwell et al., 1970; Galal and Awgichew, 1981), as well as from northeastern Brazil using Morada Nova (Figueiredo et al., 1982; Fernandes, 1985; Figueiredo, 1986), indicate similar effects of type of birth on lamb growth traits.

The gradual decrease of maternal effect as indicated by birth type and dam age on size as the lamb increases in age (Figure 1) can be explained, at least in part, by the stage of development at which the young are born (Hammond, 1961). For example, in the horse, differences in birth size tend to persist into adult life because the legs reach almost full length before birth (Walton and Hammond, 1938). In contrast, the cannon bone in sheep is not fully developed at birth and the maternal effect on size tends to diminish and the individual effect to increase with age, although weight differences persist for many months (Hunter, 1956).

Lambs out of 2-yr-old ewes tended to be lighter $(P<.01)$ at birth and older ages than were lambs out of older ewes. Lambs out of 6-yr-old ewes were heavier $(P<.01)$ at birth and older ages than were lambs out of older and younger ewes. Thus, growth of lambs tended to increase with age of dam up to 6 yr of age (i.e., when the dam was fully mature) and then as the dam aged past $6 \mathrm{yr}$ tended to decrease gradually (Table 3). Young dams that had not reached adult size continued to grow during pregnancy and thus competed with the fetus for available nutrients. The effect of excessive internal fat, which may be found in older ewes, to prevent full expansion of the gravid uterus (Hafez, 1969) was not likely to have been present in the ewes of the present study.

The general trend for the effect of age of ewe on early lamb growth was curvilinear with maximum weight of progeny from intermediate ages of ewes and lower performance from progeny of very young and aged ewes. Age effects were quadratic for BWT $(P<.05)$, WW $(P<.01)$, and $8 W(P<.05)$ but were nonsignificant at older ages even though lambs were similar in absolute size, as at weaning. However, the quadratic model did not account for all the significant effects of age of dam on BWT. Many previous reports (Blackwell and Henderson,
1955; Vesely et al., 1977; Alrawi et al., 1982; Figueiredo, 1986) have indicated that quadratic regressions of early lamb growth measures on age of dam reached a maximum at 5 to $6 \mathrm{yr}$ of age.

Sex of lamb contributed significantly to the variability of lamb growth. Males outweighed females for all the weight traits and the trend for the difference increased as age increased (Table 3, Figure 1), in general agreement with observations of Hafez (1969). Such a trend in the effect of sex on body weight might be attributed to different physiological functions in the two sexes, mainly of hormonal mediation, that tend to become more pronounced as animals approach sexual maturity. Similar findings were reported by Brown et al. (1961), Dickerson et al. (1972), and Alrawi et al. (1982) in other breeds of sheep and by Fernandes (1985) and Figueiredo (1986) working with the Morada Nova in northeastern Brazil.

Breed effect contributed $(P<.01)$ to the variation in all the lamb growth traits (Table 2). There were significant differences among the means of the three breeds for lamb weight at all ages (Table 3 ) in the same order indicated by weights of ewes. Because all weights were adjusted for type of birth, actual weights for Morada Nova lambs would be lighter than shown because of their higher lambing rate (PR = 1.82 vs 1.39 or 1.31 of the other two breeds). The Brazilian Somali lambs were, on average, the lightest, and the Santa Ines lambs were the heaviest across all ages. The Morada Nova lambs tended to be, on average, intermediate, but were closer in weight to the Brazilian Somali. Several studies (Figueiredo et al., 1982, 1983) reported significant size differences among the same three breeds under similar environmental conditions. The relative effect of breed on variability tended to increase postwean. ing as maternal effect decreased (Figure 1).

In general, the smallest and slowest-growing breed had lower sensitivity to yearly variation than did the two larger breeds. The largest breed was the most productive in terms of weight of lambs weaned per ewe.

\section{Ewe Production of Lamb}

The analysis of variance and least squares means for LWB and LWW per ewe are given in Tables 4 and 5, respectively. Ewe total lamb weight produced at birth and weaning were affected $(P<.01)$ by year of birth. Ewes lambing in the wetter years tended to have higher LWB and LWW than did those lambing in the relatively drier years. These year differences apparently resulted mainly from yearly variation in forage availability caused by seasonal rainfall differences. These findings are consistent with those of Fernandes (1985) and Figueiredo (1986) working 
Table 4. Analysis of variance of ewe total lamb weight born (LWB), ewe total lamb weight weaned (LWW), ewe lambing weight (EWT), and ewe prolificacy rate (PR)

\begin{tabular}{|c|c|c|c|c|c|c|c|c|}
\hline \multirow{2}{*}{$\begin{array}{l}\text { Source of } \\
\text { variation }\end{array}$} & \multicolumn{2}{|c|}{ LWB } & \multicolumn{2}{|c|}{ LWW } & \multicolumn{2}{|c|}{ EWT } & \multicolumn{2}{|c|}{ PR } \\
\hline & $d f$ & F & $d f$ & $\mathbf{F}$ & $d f$ & $\mathrm{~F}$ & df & F \\
\hline Breed (B) & 2 & $\star \star$ & 2 & $\star \star \star$ & 2 & $\star \star *$ & 2 & ** \\
\hline Sire/B & 17 & ** & 17 & $\star \star$ & - & - & - & - \\
\hline Type of birth (T) & 1 & $\star \star$ & 1 & $* *$ & 1 & - & - & - \\
\hline Year of birth (R) & 3 & $\star \star$ & 3 & 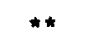 & 3 & $\star \star \star$ & 3 & NS \\
\hline Age of ewe (A) & 6 & ** & 6 & $\mathrm{NS}^{\mathrm{a}}$ & 6 & $\star \star$ & $\theta$ & $* *$ \\
\hline $\mathbf{R} \times \mathbf{B}$ & - & - & - & - & 6 & $t$ & $\theta$ & * \\
\hline$R \times T$ & 3 & ** & 3 & ** & 3 & $\star \star \star$ & - & - \\
\hline$R \times A$ & - & - & - & - & - & - & 18 & ** \\
\hline
\end{tabular}

with the Morada Nova sheep under similar environmental conditions.

Age of ewe differences were significant $(P<.01)$ only for LWB (Table 4). Young ewes produced, on average, the lightest, whereas mature ewes produced the heaviest, LWB (Table 5). Ewe total lamb weight born tended to be curvilinear with age of ewe; weights increased from $3.2 \mathrm{~kg}$ at $2 \mathrm{yr}$ to $3.7 \mathrm{~kg}$ at $6 \mathrm{yr}$ and then decreased to 3.4 at $7 \mathrm{yr}$. These findings are consistent with those reported by Sidwell et al. (1964), Hohenboken et al. (1976), and Fernandes (1985).

Type of birth was significantly associated with both ewe and lamb weight characters. Several reports (Turner et al., 1962; Turner, 1969; Bradford, 1985) have suggested that increasing multiple births in sheep may be a method to increase meat production from a given resource. However, increasing efficiency of meat production systems through increasing multiple births depends, to a great extent, on the prevailing environmental production conditions (Bradford, 1985). In the present study, single lambing produced 2.7 and $18.7 \mathrm{~kg}$ and twin lambing produced 4.2 and $27.9 \mathrm{~kg}$ at birth and weaning, respectively. Thus, there was, on average, approximately $50 \%$ greater lamb weight weaned per ewe lambing for twins. Figueiredo (1986) reported $77 \%$ greater lamb

Table 5. Least squares means (LSM) and standard errors (SE) for ewe total lamb weight born (LWB), ewe total lamb weight weaned (LWW), ewe lambing weight (EWT), and ewe prolificacy rate (PR)

\begin{tabular}{|c|c|c|c|c|c|c|c|c|c|}
\hline \multirow{2}{*}{$\begin{array}{l}\text { Main } \\
\text { effect }\end{array}$} & \multicolumn{2}{|c|}{ LWB, kg } & \multicolumn{2}{|c|}{ LWW, kg } & \multicolumn{2}{|c|}{ EWT, kg } & \multicolumn{3}{|c|}{ PR } \\
\hline & LSM \pm & $\pm S E$ & $\mathrm{LSM} \pm$ & $\mathrm{SE}$ & $\operatorname{LSM} \pm$ & $\mathrm{SE}$ & LSM & \pm & SE \\
\hline \multicolumn{10}{|l|}{ Breed } \\
\hline Somali & $2.8 \pm$ & .1 & $20.2 \pm$ & .7 & $27.9 \pm$ & .4 & 1.39 & \pm & .05 \\
\hline Santa Ines & $4.0 \pm$ & .1 & $26.9 \pm$ & .8 & $39.8 \pm$ & .5 & 1.31 & \pm & .05 \\
\hline Morada Nova & $3.4 \pm$ & .1 & $22.8 \pm$ & .7 & $30.6 \pm$ & .4 & 1.82 & \pm & .05 \\
\hline \multicolumn{10}{|l|}{ Type of birth } \\
\hline Single & $2.7 \pm$ & t .1 & $18.7 \pm$ & .5 & $32.3 \pm$ & .4 & & - & \\
\hline Twin & $4.2 \pm$ & .1 & $27.9 \pm$ & .6 & $33.2 \pm$ & .3 & & - & \\
\hline \multicolumn{10}{|l|}{ Year of birth } \\
\hline 1880 & $3.3 \pm$ & \pm .1 & $22.9 \pm$ & .8 & $29.6 \pm$ & .6 & 1.61 & \pm & .08 \\
\hline 1881 & $3.1 \pm$ & \pm .1 & $23.8 \pm$ & .7 & $32.1 \pm$ & .5 & 1.50 & \pm & .07 \\
\hline 1882 & $4.0 \pm$ & .1 & $25.6 \pm$ & .6 & $36.8 \pm$ & .5 & 1.40 & \pm & .06 \\
\hline 1883 & $3.3 \pm$ & 5.1 & $20.8 \pm$ & .8 & $32.6 \pm$ & .4 & 1.49 & \pm & .05 \\
\hline \multicolumn{10}{|l|}{ Age of ewe, yr } \\
\hline 2 & $3.2 \pm$ & t.1 & $22.4 \pm$ & .6 & $29.8 \pm$ & .5 & 1,26 & \pm & .08 \\
\hline 3 & $3.5 \pm$ & t.1 & $23.2 \pm$ & .7 & $31.3 \pm$ & .6 & $1.2 \theta$ & \pm & .10 \\
\hline 4 & $3.3 \pm$ & t.1 & $22.5 \pm$ & .8 & $31.4 \pm$ & .8 & 1.48 & \pm & .08 \\
\hline 5 & $3.4 \pm$ & .1 & $23.5 \pm$ & .7 & $31.8 \pm$ & .6 & 1.65 & \pm & .07 \\
\hline 6 & $3.7 \pm$ & $t .1$ & $24.5 \pm$ & .7 & $34.9 \pm$ & .7 & 1.66 & \pm & .08 \\
\hline 7 & $3.4 \pm$ & \pm .1 & $23.5 \pm$ & .7 & $34.6 \pm$ & .7 & 1.77 & \pm & .08 \\
\hline 8 & $3.5 \pm$ & \pm .1 & $23.4 \pm$ & .8 & $35.6 \pm$ & .8 & 1.43 & \pm & .13 \\
\hline
\end{tabular}




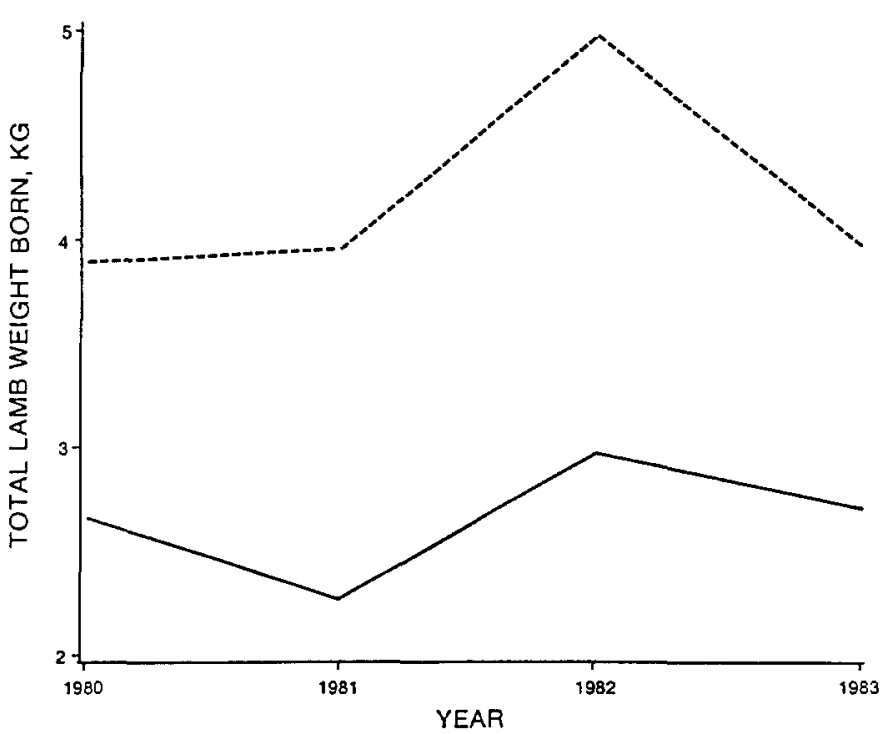

Figure 2. Least squares means of total lamb weight born (kilograms) per ewe for single (solid line) and twin (dashed line) lambs for each year.

weight weaned per ewe lambing for twins in the Morada Nova breed.

Type of birth $\times$ year of birth interaction terms for LWB and LWW were significant (Table 4). Differences between singles and twins for LWB and LWW changed significantly across years but did not reverse rank (Figures 2 and 3 ). These differences tended to increase in wet years and decrease in dry years. For example, in 1982, a relatively wet year, the respective differences between singles and twins were 2 and $11.4 \mathrm{~kg}$ for LWB and LWW, respectively. Conversely, in 1983 , a relatively dry year, the respective differences between singles and twins were 1.3 and $6.1 \mathrm{~kg}$ for LWB and LWW.

The interaction between type of birth and year of birth is important in addressing the issue of multiple lambing in range sheep. Different conclusions can be drawn by comparing different management schemes in different yearly environ. ments. Generally, in good years there is more abundant forage of good quality to support a high twinning rate and the advantage of twins is more marked (Figure 3). In poor years, differences between singles and twins were smaller for LWB and LWW (Figures 2 and 3) and, in addition, mortality rate of twins tended to be higher (Figueiredo, 1986). Therefore, this interaction must be taken into consideration before any general conclusion can be drawn about the role of type of birth in determining ewe total lamb production at birth and weaning.

Breed differences were significant for LWB and LWW characters (Table 4). The Brazilian Somali ewes had, on average, the lightest LWB and LWW

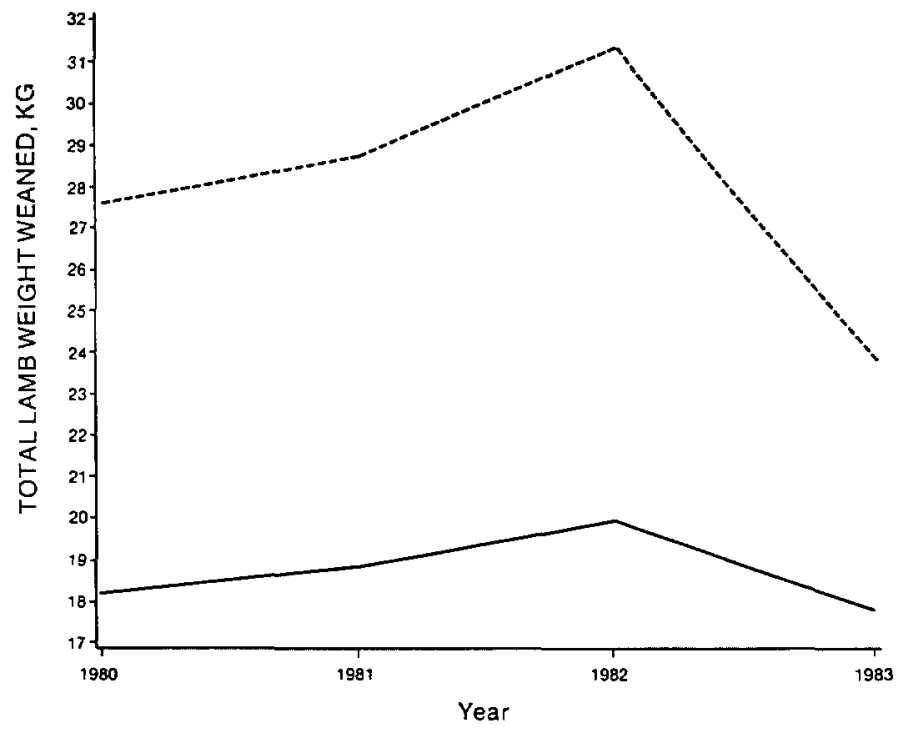

Figure 3. Least squares means of total lamb weight weaned (kilograms) per ewe for single (solid line) and twin (dashed line) lambs for each year.

and the Santa Ines had the heaviest LWB and LWW (Table 5). The Morada Nova ewes tended to be intermediate but closer to the Brazilian Somali. Santa Ines ewes produced, on average, approximately $18 \%$ more LWB and LWW than did the Morada Nova. The higher prolificacy rate in the Morada Nova was accompanied by a relatively higher mortality rate from birth to weaning (Figueiredo, 1986).

\section{Ewe Lambing Weight}

The analysis of variance and least squares means for EWT are presented in Tables 4 and 5, respectively. There were differences $(P<.01)$ in least squares means for EWT between one wet year (1982) and one dry year (1983) and between the two wet years (1981 and 1982). These findings indicate that, in general, both quantity and distribution of rainfall affected EWT.

Type of birth differences contributed $(P<.05)$ to the variability in EWT. Ewes with twins had higher EWT than did ewes with single lambs. Ageof-dam differences also contributed $(P<.01)$ to the variability of ewe EWT. Ewe lambing weight increased with age of ewe from $29.8 \mathrm{~kg}$ at $2 \mathrm{yr}$ to $35.6 \mathrm{~kg}$ at $8 \mathrm{yr}$.

The Brazilian Somali ewes were, on average, the lightest $(27.9 \mathrm{~kg}$ ) at lambing, the Santa Ines ewes were the heaviest $(39.9 \mathrm{~kg})$ and the Morada Nova ewes were intermediate $(30.6 \mathrm{~kg})$ but closer to the Brazilian Somali. The breed $x$ year of birth interaction for EWT was significant (Table 4), indicating that the relative magnitude of differences among breeds for this character did not 


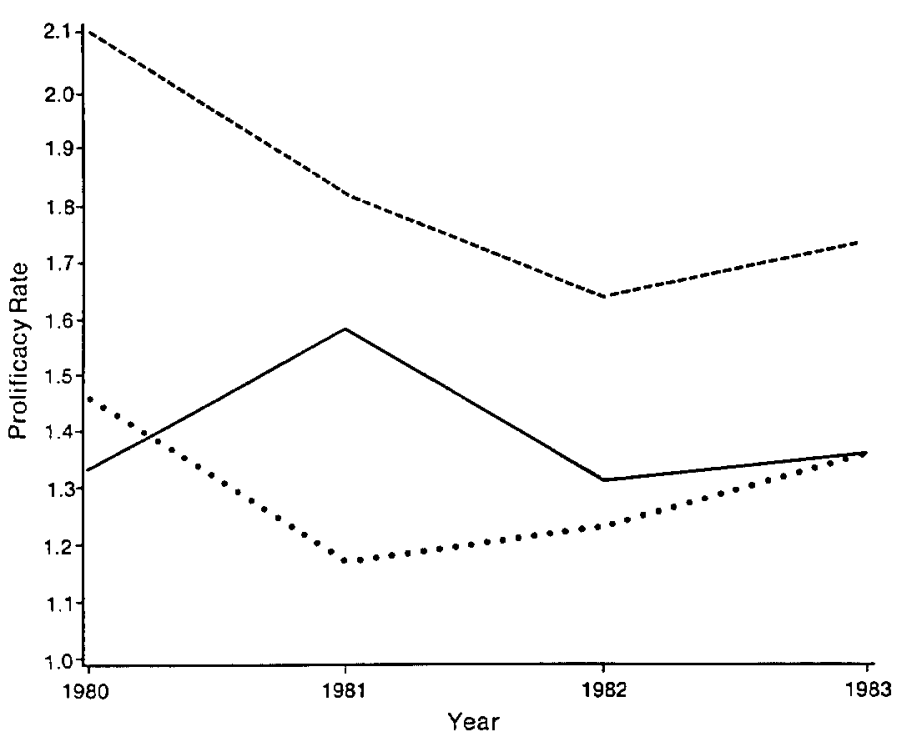

Figure 4. Least squares means of ewe prolificacy rate of Brazilian Somali (solid line), Morada Nova (dashed line), and Santa Ines (dotted line) ewes for each year.

remain constant across years. In 1980 the Morada Nova had the same EWT as the Brazilian Somali. However, in 1982 the Morada Nova was $13 \%$ heavier than the Brazilian Somali. The Santa Ines and Brazilian Somali EWT means differed by 35 and $50 \%$ in 1980 and 1882 , respectively. These differences among the three breeds for EWT, which were heterogeneous across years, emphasized the influence of yearly variation on sheep production and reproduction in the northeastern region of Brazil. The Brazilian Somali exhibited lower sensitivity to yearly variation of EWT than did the Morada Nova or the Santa Ines.

\section{Prolificacy Rate}

Prolificacy is a measure related to the number of fertile ova produced per ewe at each estrus. In this study it was measured as the average number of lambs born per ewe lambing. The analysis of variance and least squares means for $P R$ are presented in Tables 4 and 5 , respectively. Prolificacy rate was affected by breed $(P<.01)$ and age of ewe $(P<.01)$. Figueiredo (1986) reported that the previous weaning status of ewes had a significant effect on their PR in the Morada Nova under similar environmental conditions. In the present study no data were available on previous weaning status of ewes.

Breed differences were a source of variation ( $P$ $<.01)$ for PR. The Morada Nova was the most prolific breed $(182 \%)$, followed by the Brazilian Somali $(139 \%)$ and the Santa Ines (131\%). Age of ewe differences contributed $(P<.01)$ to the variability in PR. Lambs born per ewe lambing increased curvilinearly with age of ewe from $126 \%$ at $2 \mathrm{yr}$ to $177 \%$ at $7 \mathrm{yr}$ and then decreased to $143 \%$ at $8 \mathrm{yr}$.

Two interactions involving year of birth were significant: breed $\times$ year $(P<.05)$ and age of ewe $\times$ year $(P<.01)$. These interactions place limitations on the interpretation of breed and age of dam effects because the order or magnitude of differences of PR may change from one subclass to another. For example, 1980 was the most prolific year for both the Santa Ines and the Morada Nova, whereas it was an average prolific year for the Brazilian Somali (Figure 4). In contrast, 1981 was the most prolific year for the Brazilian Somali, but the Santa Ines had its lowest PR. Also, breed rankings of ewe prolificacy rate were erratic among years.

For example, the respective PR for the Brazilian Somali and the Santa Ines were 1.3 and 1.6 in 1980 and 1.5 and 1.2 in 1981. Furthermore, a higher preweaning mortality rate of twin lambs resulted in no significant differences of prolificacy among breeds when prolificacy was measured as lambs weaned per ewe lambing (Rajab et al., 1991). The age of dam $\times$ year of birth interaction showed that the most prolific ewe ages in 1980,1981, and 1983 were 6,7 , and $5 \mathrm{yr}$, respectively.

The general conclusion that can be drawn from the prolificacy analysis is that the Morada Nova is the most prolific of the three breeds and the Brazilian Somali and Santa Ines tend to have similar prolificacy rates.

\section{Implications}

Tropical range areas that are subject to uncertain seasonal rainfall patterns that cause scarcity and low quality of forage require a well-adapted breed of sheep to attain maximal offtake. Choice of a breed that is most productive as a flock when subjected to these environmental stresses requires compromising genetic potential for the primary production characters. Given certain levels of risk aversion and environmental constraints, major inputs and outputs must be considered simultaneously to make effective breed choices and to establish within-breed selection goals.

\section{Literature Cited}

Alrawi, A. A., F. S. Badawi, S. I. Said, and M. S. Farag. 1982. Genetic and phenotypic parameter estimates for growth traits in Awassi sheep. Indian J. Anim. Sci. 52:897.

Blackburn, H. D., and T. C. Cartwright. 1887. Description and validation of the Texas A\&M sheep simulation model. J. Anim. Sci. 65:373.

Blackwell, R. L., and C. R. Henderson. 1955. Variation in fleece weight, weaning weight and birth weight of sheep under 
farm conditions. J. Anim. Sci. 14:831.

Bradford, G. E. 1985. Selection for litter size. In: R. B. Land and D. W. Robinson (Ed.) Genetics of Reproduction in Sheep. pp 3-18. Butterworths, London.

Bradley, B. P., A. B. Chapman, A. L. Pope, and C. O. Rydberg. 1872. Two- and three-way crosses estimating combining ability of Suffolk, Targhee and Shropshire breeds of sheep. J. Anim. Sci. 34:541.

Brown, C. J., C. A. Bangus, and S. Sabin. 1961. Evaluation of factors affecting the growth of spring lambs. Arkansas Exp. Sta. Bull. 648 .

Dickerson, G. E., H. A. Glimp, H. J. Tuma, and K. E. Gregory. 1872. Genetic resources for efficient meat production in sheep. Growth and carcass characteristics of ram lambs of seven breeds. J. Anim. Sci. 34:940.

Eltawil, E. A., L. N. Hazel, G. M. Sidwell, and C. E. Terrill. 1970. Evaluation of environmental factors affecting birth, wean. ing and yearling traits in Navajo sheep. J. Anim. Sci. 31: 823.

Fernandes, A.A.O. 1885. Genetic and environmental factors af fecting growth and reproduction characters of Morada Nova sheep in northeast Brazil. M. S. Thesis. Texas A\&M Univ., College Station.

Figueiredo, E.A.P. 1880. Prolific tropical sheep. In: I. L. Mason (Ed.) pp 53-58. FAO Animal Production and Health Paper No. 17.

Figueiredo, E.A.P. 1988. Potential breeding plans developed from observed genetic parameters and simulated genotypes for Morada Nova sheep in northeast Brazil. Ph.D. Dissertation. Texas A\&M Univ., College Station.

Figueiredo, E.A.P., E. R. Oliveira, C. Bellaver, and A. A. Simplicio. 1083. Hair sheep performance in Brazil. In: H. A. Fitzhugh and G. E. Bradford (Ed.) Hair Sheep of Western Africa and the Americas. pp 125-140. Westview Press, Boulder, $\mathrm{CO}$.

Figueiredo, E.A.P., A. A. Simplicio, and K. P. Pant. 1882. Evaluation of sheep breeds for early growth in tropical North-East Brazil. Trop. Anim. Health Prod. 14:218.

Galal, E.S.E., and K. Awgichew. 1881. Ethiopian Adal sheep: Genetic and environmentel factors affecting body weight and postweaning gain. Int. Goat Sheep Res. 1:1310.

Glimp, H. A. 1871. Effect of breed and mating season on reproductive performance of sheep. J. Anim. Sci. 32:1176.

Hafez, E.S.E. 1868. Introduction to animal growth. In: E.S.E. Hafez and I. A. Dyer (Ed.) Animal Growth and Nutrition. pp 1-17. Lea and Febiger, Philadelphia, PA.

Hammond, J. 1961. Growth in size and body proportions in farm animals. In: Growth in Living Systems. Basic Books, New York.

Hohenboken, W., K. Corum, and R. Bogart. 1976. Genetic, environmental and interaction effects in sheep. I. Reproduction and lamb production per ewe. J. Anim. Sci. 42:289.
Hunter, G. L. 1958. The maternal influence on size in sheep. J. Agric. Sci. 48:36.

Kilkenny, J. B. 1878. Nutrition and management of lactating ewes in systems for meat production under intensive grazing systems. In: J. G. Boyazoglu and T. T. Treacher (Ed.) Milk production in the Ewe. pp 101-115. Eur. Assoc. Anim. Prod. Publ. No. 23.

Pfister, J. A. 1883. Nutrition and feeding behavior of goats and sheep grazing deciduous shrub-woodland of northeastern Brazil. Ph.D. Dissertation. Utah State Univ., Logan.

Phillips, R. W., and W. M. Dawson. 1840. Some factors affecting survival, growth and selection of lambs. USDA Circular No. 538. Washington, DC.

Phillips, R. W., J. A. Stoehr, and A. W. Brier. 1940. Growth in Corriedale and Rambouillet sheep under range conditions. Proc. Am. Soc. Anim. Prod. pp 173.

Rajab, M. H. 1987. Simulation of genetic and environmental interaction of three tropical hair sheep breeds for meat production. Ph.D. Dissertation. Texas. A\&M Univ., College Station.

Rajab, M. H., H. D. Blackburn, T. C. Cartwright, and E.A.P. Figueiredo. 1991. Simulation of genetic and environmental interaction of three tropical hair sheep breeds. J. Anim. Sci. 68:4397.

SAS. 1882. SAS User's Guide: Statistics. SAS Inst. Inc., Cary, NC.

Sidwell, G. M., D. O. Everson, and C. E. Terrill. 1964. Lamb weights in some pure breeds and crosses. J. Anim. Sci. 23: 105.

Sidwell, G. M., and L. R. Miller. 1971. Production in some pure breeds of sheep and their crosses. I. Reproductive efficiency in ewes. J. Anim. Sci. 32:1084.

Sidwell, G. M., J. L. Ruttle, and E. E. Ray. 1870. Improvement of Navajo sheep. New Mexico Agric. Exp. Sta. Rep. No. 172.

Turner, H. N. 1968. Factors affecting multiple births in sheep. Anim. Breed. Abstr. 21:211.

Turner, H. N., R. H. Hayman, L. K. Triffitti, and R. W. Prunster. 1962. Response to selection for multiple births in Australian Merino: A progress report. Anim. Prod. 4:165.

Vesely, J. A., G. C. Kozub, and H. F. Peters. 1977. Additive and non-additive genetic effects on growth traits in matings among Romnelet, Columbia, Suffolk and North Country Cheviot breeds. Can. J. Anim. Sci. 57:233.

Walton, A., and J. Hammond. 1938. The maternal effect on growth and conformation in Shire horse-Shetland pony crosses. Proc. R. Soc. (Biol.):125.

Warwick, B. L., and T. C. Cartwright. 1958. Adjustment of milk lamb weaning weights to a standard age. J. Anim. Sci. 17: 521. 